RECYT

Año 22 / № 33 / 2020 / 47-57

\title{
Biorefinería para producir bioplástico y proteína a partir de suero de leche utilizando el simulador ASPEN
}

\section{Biorefinery to produce bioplastic and protein from whey using the ASPEN simulator \\ Biorefinaria para produzir bioplástico e proteína dosoro do leite usando o simulador ASPEN}

Flávia F. Wândega1 * , Eduardo R. Braga1', Sérgio Roberto G. S. Filho², Fernanda F. Wândega ${ }^{3}$, Luiz Antônio M. Pontes'ㄹ, Regina F. Vianna'

1- Universidade Federal da Bahia (UFBA), Programa de Pós-Graduação em Engenharia Química (PPEQ). Bahia, Brazil.

2- Universidade Federal da Bahia (UFBA), Graduação em Engenharia Química. Bahia, Brazil.

3- Universidade Federal da Bahia (UFBA), Graduação em Engenharia Civil. Bahia, Brazil.

* E-mail: flavia_wandega@hotmail.com

\section{Resumen}

Recibido el 23 de diciembre de 2018, Aprobado el 9 de noviembre de 2019.

\begin{abstract}
El objetivo del trabajo fue evaluar la viabilidad técnica y económica de instalar una biorefinería integrada a una industria láctea para usar los efluentes de suero de leche y producir bioplástico polihidroxibutirato (PHB) y proteína. Basado en la literatura científica, se establecieron las operaciones unitarias del proceso de producción de PHB y proteína con el Simulador Aspen Plus versión 8.8. Se usaron cepas recombinantes de Escherichia coli para la biosíntesis metabólica de PHB con solvente de carbonato de propileno y ultrafiltración para extraer la proteína. Desde el punto de vista técnico y económico, la instalación de una biorefinería integrada a una industria láctea que procesa como mínimo 250000 L de leche por día fue viable.
\end{abstract}

Palabras clave: Biorefinería; Bioplástico; Proteína; Suero de leche; Simulador Aspen.

\section{Abstract}

The aim of this work was to evaluate the technical and economic feasibility of installing a biorefinery, capable of being integrated into the dairy industry to use whey effluents and to produce bioplastic polyhydroxybutyrate (PHB) and protein. Based on scientific literature, the unit operations of the PHB and protein production processes were established through the Aspen Plus Simulator, 8.8 version. Escherichia coli recombinant strains were used for the metabolic biosynthesis of PHB with propylene carbonate solvent while ultrafiltration was used to extract the protein. The installation of a biorefinery, integrated to a dairy industry that processes at least $250000 \mathrm{~L}$ of milk per day was viable from both a technical and an economic viewpoint.

Keywords: Biorefinery; Bioplastic; Protein; Whey of milk; Aspen Simulator.

\section{Resumo}

O objetivo do trabalho foi avaliar a viabilidade técnica e econômica da instalação de uma biorrefinaria integrada à indústria de laticínios para o uso de efluentes de soro de leite e produção do bioplásticopolihidroxibutirato (PHB) e proteína. Com base na literatura científica, as operações unitárias do processo de produção de PHB e proteína foram estabelecidas com o Simulador Aspen Plus versão 8.8. Cepas recombinantes de Escherichia coli foram utilizadas para a biossíntese metabólica de PHB com o solvente carbonato de propileno e ultrafiltração para extrair a proteína. Do ponto de vista técnico e econômico, a instalação de uma biorrefinaria integrada a uma indústria de laticínios que processa pelo menos 250.000 L de leite por dia é viável.

Keywords: Biorrefinaria; Bioplástico; Proteína; Soro de Leite; Simulador Aspen.

Introdução

Atualmente, sabe-se que é de extrema importância a substituição da atual matriz energética para alternativas mais renováveis, sustentáveis e que gerem menor impacto ao ambiente. Então, a partir dessa conscientização, vários países têm se atentado para o conceito de biorrefinaria, o qual é semelhante ao de uma refinaria de petróleo conven- 
cional, porém o principal insumo do refino é a biomassa [1]. O Brasil possui uma grande biodiversidade, o que o torna um potencial país para a implantação de biorrefinarias. Entretanto, a biodiversidade e disponibilidade de matéria-prima não são os únicos fatores que influenciam a análise de um negócio, sendo, então, necessário um estudo de viabilidade técnica e econômica para resultados mais conclusivos. O presente trabalho tem como propósito fazer os estudos mencionados anteriormente visando à implantação de uma biorrefinaria no Brasil e, dessa forma, expondo a devida metodologia para o desenvolvimento do projeto.

A biomassa lignocelulósica brasileira apresenta um grande potencial para ser aplicada em biorrefinarias. Entretanto, esse tipo de biomassa está sujeita à influência da sazonalidade na produção [2]. Desta forma, os resíduos provindos das fontes pecuárias merecem uma maior atenção, principalmente o leite, já que o efluente de sua produção pode ser utilizado para a produção de biopolímeros. Da literatura, por exemplo, tem-se a informação que, para cada $1 \mathrm{~kg}$ de queijo produzido, gera-se $9 \mathrm{~kg}$ de soro de leite [3]. Com relação à produção brasileira de queijo, esta atingiu cerca de 3,4 milhões de toneladas no ano de 2016 [3]. Logo, a partir das informações mencionadas anteriormente, estima-se que a produção brasileira de soro de leite foi de 30,6 milhões de toneladas no ano de 2016.

Os biopolímeros são definidos como macromoléculas que podem ser sintetizadas por organismos vivos e, pelo menos uma etapa de sua degradação, acontece através do metabolismo de organismos, os quais estão presentes no meio ambiente [4]. É fato que estes possuem grandes vantagens quando comparado aos polímeros de origem petrolífera, já que, por serem biodegradáveis, não se acumulam no meio ambiente como os polímeros derivados do petróleo [5].

O polihidroxibutirato, PHB, é um exemplo desses biopolímeros e pode ser sintetizado, de forma biológica, a partir do soro do leite. A produção industrial do PHB, no Brasil, começou no ano de 2000 pela PHB industrial, utilizando a cana-de-açúcar como matéria-prima. O PHB pode ser utilizado em embalagens, lonas e peças automotivas [6].

Em termos biotecnológicos, o processo da produção dos bioplásticos em escala industrial foi descrito por Byrom (1987) [7] e este é, basicamente, realizado em um reator batelada bioquímico. Entretanto, cabe ressaltar que o custo do processo de transformação da fonte reserva de carbono em plásticos biodegradáveis pode ser alto, mas isto é devido, principalmente, aos elevados custos na obtenção da matéria-prima, já que representam $40 \%$ do total do custo de produção [8]. Dessa forma, tem-se o soro do leite efluente da produção das indústrias de lacticínios, como uma boa alternativa de baixo custo da produção desses bioplásticos.

O processo produção da $\mathrm{PHB}$, basicamente, consiste em uma reação bioquímica com uma fonte de carbono (soro do leite, melaço, cana-de-açúcar,etc.), a qual ocorre no interior de um micro-organismo e em um meio com limitação de certos nutrientes, como oxigênio, nitrogênio, fósforo e magnésio, entre outros. Dentre esses micro-organismos, pode ser visto, na literatura, que Cepas recombinantes da bactéria Escherichia coli produziram,de forma efetiva, o poliéster PHB e, assim, dados de alta concentração e produtividade referentes a esse processo foram obtidos [9].

A PHB Industrial S.A, localizada na Usina da Pedra, no município de Serrana, pertencente ao estado de São Paulo, é a única empresa produtora de PHB no Brasil. O PHB produzido recebe o nome comercial de Biocycle e é obtido a partir da fermentação da cana-de-açúcar, realizada por micro-organismos [10]. A produção em escala piloto desse polímero teve início no ano de 1995, sendo que a capacidade de produção dessa planta era, inicialmente, da ordem de 5 ton/ano. Entretanto, em 1997, foi feita uma avaliação técnica e econômica com base nos dados retirados da planta piloto e, assim, ocorreram alterações no processo e no dimensionamento dos equipamentos. Dessa forma, diante do exposto nas linhas anteriores, no ano de 2000, a planta conseguiu aumentar sua produção para 50 ton/ano. A empresa pretende transformar a escala piloto em industrial para a produção de 30000 ton/ano de PHB [10].

A avaliação econômica e a simulação empregada neste trabalho foram feitas com o objetivo de se determinar quantitativamente e qualitativamente o processo de produção do PHB a partir do soro do leite. Para essa determinação, foi considerado, com base na literatura, que o solvente e os microrganismos empregados foram o carbonato de propileno e cepas recombinante da bactéria Escherichia coli.

Para a análise de viabilidade econômica, quantificou-se as matérias-primas e as utilidades das etapas do processo, incluindo a inoculação, a qual consiste no cultivo e crescimento dos micro-organismos. Assim, foi possível também efetuar o cálculo dos custos, através da estimação de certos insumos, dimensionamento e certas premissas relativas à operação de alguns equipamentos.

Há pouca informação na literatura sobre propostas de processo de produção em escala industrial de PHB. Além disso, não foram encontrados trabalhos que façam uma análise econômica do processo descrito, que vai desde o pré-tratamento do soro de leite, proveniente de indústrias de lacticínios, até a purificação do PHB formado, incluindo o aproveitamento da proteína presente no soro de leite (Whey Protein).

O objetivo do trabalho foi avaliar a viabilidade técnica e econômica da instalação de uma biorrefinaria integrada a uma indústria de laticínios para utilizar os efluentes do soro de leite e produzir bioplásticos PHB e proteínas. 


\section{Materiais e Métodos}

\section{Caracterização da Reação e Descrição do processo}

O artigo base utilizado para a caracterização da reação foi o de AHN; PARK e LEE, 2000 [9], que conduziu o experimento com a mais elevada concentração de lactose: $280 \mathrm{~g} / \mathrm{L}$. Devido a essa concentração, a ampliação do processo em escala industrial foi facilitada. O microorganismo utilizado foi: Escherichia coli.

A Tabela 1 mostra os principais dados retirados desse artigo para a produção bioquímica de PHB a partir do soro do leite.

Tabela 1: Dados para a produção bioquímica de PHB a partir do soro do leite

\begin{tabular}{|c|c|c|}
\hline Informação & Descrição & Valor \\
\hline TINOCULAÇÃO & $\begin{array}{l}\text { Tempo que leva a formação do } \\
\text { inóculo que, posteriormente, } \\
\text { será utilizado no biorreator }\end{array}$ & 96 horas \\
\hline TFERMENTAÇÃO & $\begin{array}{l}\text { Tempo que lava para os } \\
\text { microrganismos convertem a } \\
\text { lactose em PHB no biorreator }\end{array}$ & 37,5 horas \\
\hline$Y_{X / s}$ & $\begin{array}{l}\text { Rendimiento da conversão } \\
\text { do substrato em célula }\end{array}$ & $0,52 \mathrm{~g} / \mathrm{g}$ \\
\hline$Y_{p / s}$ & $\begin{array}{l}\text { Rendimiento da conversão } \\
\text { do substrato em produto }\end{array}$ & $0,42 \mathrm{~g} / \mathrm{g}$ \\
\hline \% VINÓCULO/VBIORREACTOR & $\begin{array}{l}\text { Porcentagem do volume total } \\
\text { do inóculo com relação ao } \\
\text { volume útil total do biorreator }\end{array}$ & $20 \%$ \\
\hline \% PHB/CÉLULAS & $\begin{array}{l}\text { Porcentagem de produto } \\
\text { no massa celular }\end{array}$ & $80 \%$ \\
\hline
\end{tabular}

Fonte: Ahn; Park e Lee, 2000 [9]

Como substrato principal na fermentação, utilizou-se uma solução de soro de leite com concentração de 280 $\mathrm{g} / \mathrm{L}$ de lactose mais sulfato de magnésio $\left(\mathrm{MgSO}_{4} \cdot 7 \mathrm{H}_{2} \mathrm{O}\right)$ a uma concentração de $6 \mathrm{~g} / \mathrm{L}$. Já para a etapa de inoculação, o substrato principal é uma solução de soro de leite a 40 $\mathrm{g} / \mathrm{L}$ com adição de fosfato de monopotássio $\left(\mathrm{KH}_{2} \mathrm{PO}_{4}\right)$ a 6,67 g/L, fosfato diamônico $\left[\left(\mathrm{NH}_{4}\right)_{2} \mathrm{HPO}_{4}\right]$ a $4 \mathrm{~g} / \mathrm{L}$, sulfato de magnésio a $0,8 \mathrm{~g} / \mathrm{L}$, ácido cítrico $\left(\mathrm{C}_{6} \mathrm{H}_{8} \mathrm{O}_{7}\right)$ a $0,8 \mathrm{~g} / \mathrm{L}$, ácido clorídrico $(\mathrm{HCl})$ a $0,025 \mathrm{~mol} / \mathrm{L}$, sulfato de ferro $\left(\mathrm{FeSO}_{4} \cdot 7 \mathrm{H}_{2} \mathrm{O}\right)$ a $0,05 \mathrm{~g} / \mathrm{L}$, cloreto de cálcio $\left(\mathrm{CaCl}_{2}\right)$ a $0,01 \mathrm{~g} / \mathrm{L}$, sulfato de zinco $\left(\mathrm{ZnSO}_{4} \cdot 7 \mathrm{H}_{2} \mathrm{O}\right)$ a $0,011 \mathrm{~g} / \mathrm{L}$, sulfato de manganês $\left(\mathrm{MnSO}_{4} \cdot 4 \mathrm{H}_{2} \mathrm{O}\right)$ a $0,0025 \mathrm{~g} / \mathrm{L}$, sulfato de cobre $\left(\mathrm{CuSO}_{4} .5 \mathrm{H}_{2} \mathrm{O}\right)$ a $0,005 \mathrm{~g} / 1$, molibdato de amônio $\left[\left(\mathrm{NH}_{4}\right)_{6} \mathrm{Mo}_{7} \mathrm{O}_{24} \cdot 4 \mathrm{H}_{2} \mathrm{O}\right]$ a $0,0005 \mathrm{~g} / \mathrm{L}$ e tetraborato de sódio $\left(\mathrm{Na}_{2} \mathrm{~B}_{4} \mathrm{O}_{7} \cdot 10 \mathrm{H}_{2} \mathrm{O}\right)$ a $0,0002 \mathrm{~g} / \mathrm{L}$ [9].

As considerações para a descrição do processo e resolução do balanço de massa foram determinadas através de dados obtidos na literatura cientifica. A partir desses dados experimentais de laboratório, desenvolveu-se o processo em escala industrial.

A Figura 1 mostra o fluxograma do processo proposto.

Inicialmente, o soro do leite, o qual contém a substância reagente, a lactose $(4,4 \% \mathrm{~m} / \mathrm{m})$ [11], passa por um evaporador e um vaso separador de flash (EVAP-01 E EVAFLASH), o qual remove grande parte da solução aquosa presente no substrato. Essa é uma etapa importante, pois a concentração de lactose no soro de leite deve ser de $280 \mathrm{~g} / \mathrm{L}$ [9] para assim ser utilizado como substrato da reação. Depois, o soro de leite concentrado, passa por um resfriador (RESFR-01), visto que, o processo de evaporação aumentou a temperatura do mesmo e a reação ocorre a $36^{\circ} \mathrm{C}[9]$.

A corrente resultante do processo de resfriamento passa por um ultrafiltro (FILTRO1), já que, o objetivo, nessa etapa, é a extração das proteínas do soro do leite (Whey protein) que, posteriormente, será comercializada para a produção de concentrado proteico. O método de extração utilizado para a remoção dessas proteínas é a ultrafiltração, pois, é o mais efetivo, quando comparado à filtração comum. A eficiência do método é consequência da passagem da corrente do processo por uma membrana semipermeável, resultando na concentração das proteínas [12].

Ao sair do processo de ultrafiltração, da literatura, temse a informação de que a corrente resultante de proteínas

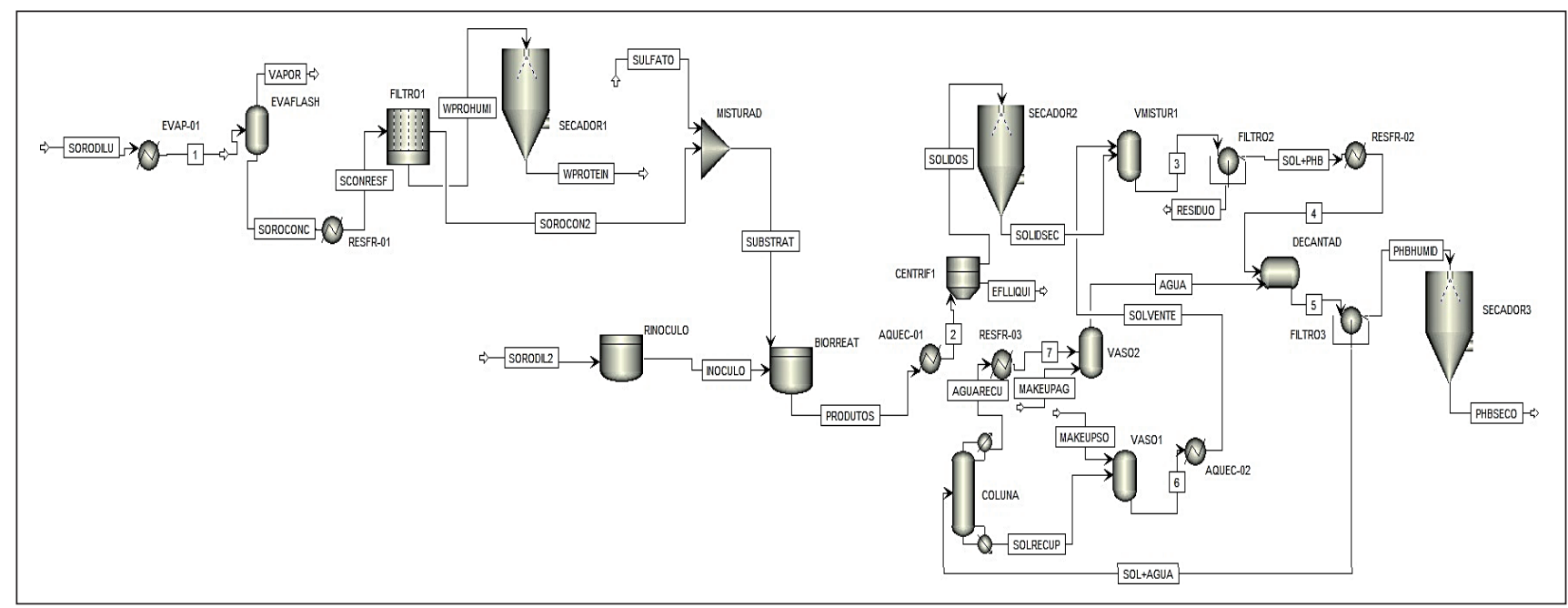

Figura 1: Processo de produção do PHB e extração das proteínas a partir do soro do leite Fonte: Simulador Aspen Plus versão 8.8 


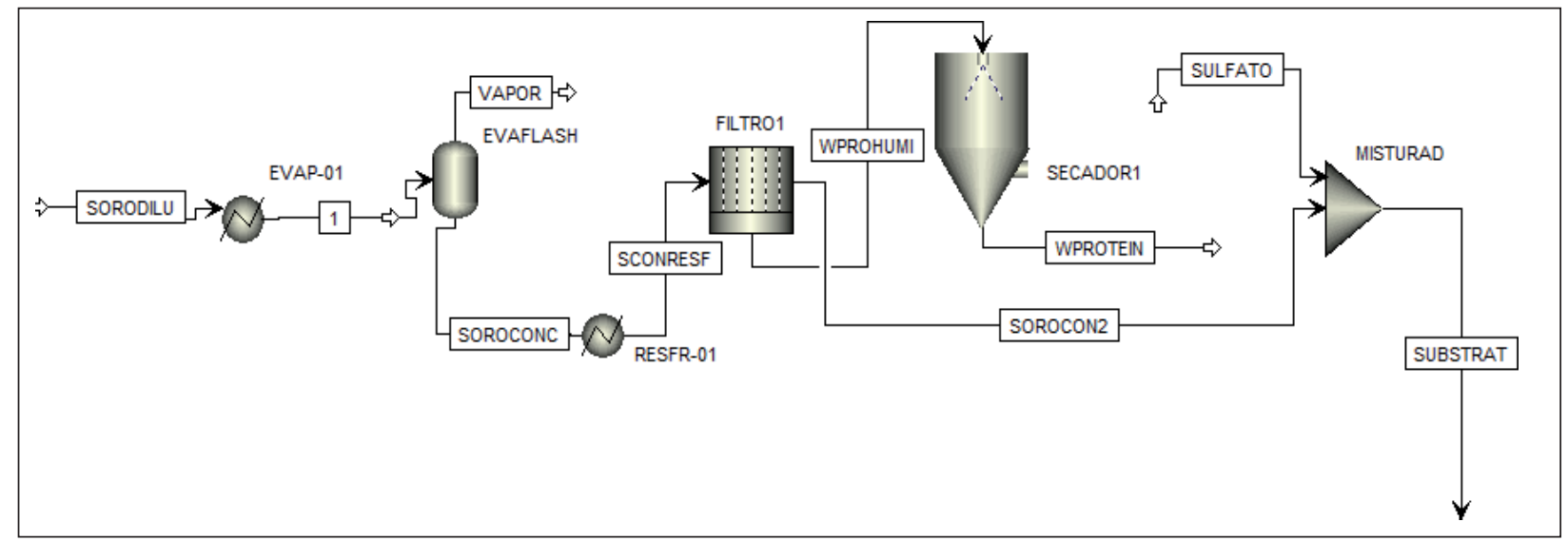

Figura 2. Fluxograma do processo de produção de PHB - Etapa antes do biorreator

Fonte: Simulador Aspen Plus versão 8.8

(concentrado) contém um teor entre 50 e $75 \%$ em base seca [12]. Então, devido ao teor de umidade contido no concentrado proteico, este passa por um secador (SECADOR1), o qual consegue remover grande parte da água, resultando, assim, na proteína com $90 \%$ de pureza (Whey protein isolada) [13].

Então, para a continuação do processo de produção de PHB, à corrente de permeado do ultrafiltro, é adicionado sulfato de magnésio, já que este também é parte do substrato reacional e, assim, uma corrente contendo esse sal se une à corrente resultante de soro (MISTURAD). Todo o processo descrito anteriormente pode ser visto na Figura 2, a qual é uma seção da Figura 1.

O reator de inoculação (RINOCULO), Figura 3, opera em batelada e este consiste no cultivo e multiplicação dos micro-organismos que serão utilizados na reação. Para isso, são adicionados a estes micro-organismos sais (cujo foram citados anteriormente) que favorecem o crescimento dos mesmos em um tempo de inoculação de, aproximadamente, 96 horas [9]. Nesse reator, é adicionada como parte substrato principal, uma corrente de soro de leite diluído. Assim, a "corrente resultante" da inoculação, após o período mencionado anteriormente, é adicionada ao biorreator também.

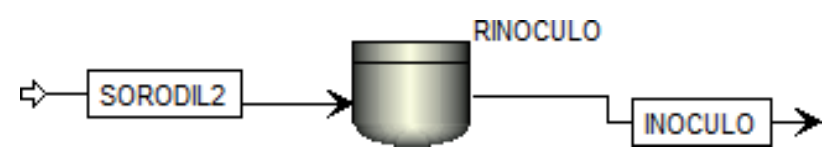

Figura 3: Fluxograma do processo de produção de PHB - Etapa do reator de inoculação

Fonte: Simulador Aspen Plus versão 8.8

De forma sucinta, o biorreator (BIORREAT), Figura 4, que opera no regime de batelada alimentada, é alimentado com um tempo de carga de, aproximadamente, 37,5 horas, com as correntes de substrato contendo soro de leite concentrado e o sulfato de magnésio, de micro-organismos provenientes do reator de inoculação e de ar [9]. A corrente de ar auxilia na fermentação, já que esse é um processo aeróbio e necessita desse gás para ocorrer. Para eliminar possíveis gases reacionais e manter a pressão, o biorreator possui uma válvula de alívio.
O período de descarga do biorreator também foi definido como 37,5 h (igual ao tempo de carga), visto que, esse também é o tempo de fermentação da reação [9].

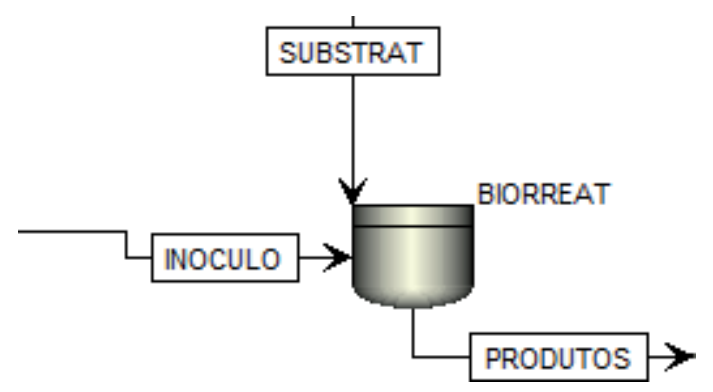

Figura 4: Fluxograma do processo de produção de PHB - Etapa do biorreator

Fonte: Simulador Aspen Plus versão 8.8

A corrente resultante do biorreator sai à temperatura ambiente e passa por um vaso de aquecimento (AQUEC-01) para alcançar a temperatura de $95^{\circ} \mathrm{C}$. Esse processo é necessário, pois auxilia no enfraquecimento da membrana celular e, assim, é possível extrair mais facilmente o PHB contido nas células de micro-organismos, pois se trata de um produto intracelular [14].

Depois do aquecimento, a corrente resultante passa por uma centrífuga (CENTRIF1), onde é possível eliminar boa parte da solução aquosa em que se encontra as bactérias com o produto resultante. Posteriormente, o permeado da centrifugação passa por um secador (SECADOR2) e, assim, elimina-se também boa parte da solução aquosa residual. A etapa seguinte é a extração (VMISTUR1), em que se adiciona o solvente, carbonato de propileno, a $150^{\circ}$ C e assim, o produto PHB é extraído das bactérias [14]. A corrente resultante da extração - com PHB, solvente e células - passa por um filtro (FILTRO2) no qual a massa de células ficará retida e se separará do solvente e do PHB. Nesse filtro, ocorre a perda de carca de $15 \%$ da massa inicial de solvente devido a sua retenção pelas células, e também ocorre a perda de $25 \%$ da massa total de PHB, pois devido a constante reutilização do solvente, a eficiência da extração é perdida e parte do PHB permanece nas células [15]. A corrente de permeado resultante passa por 


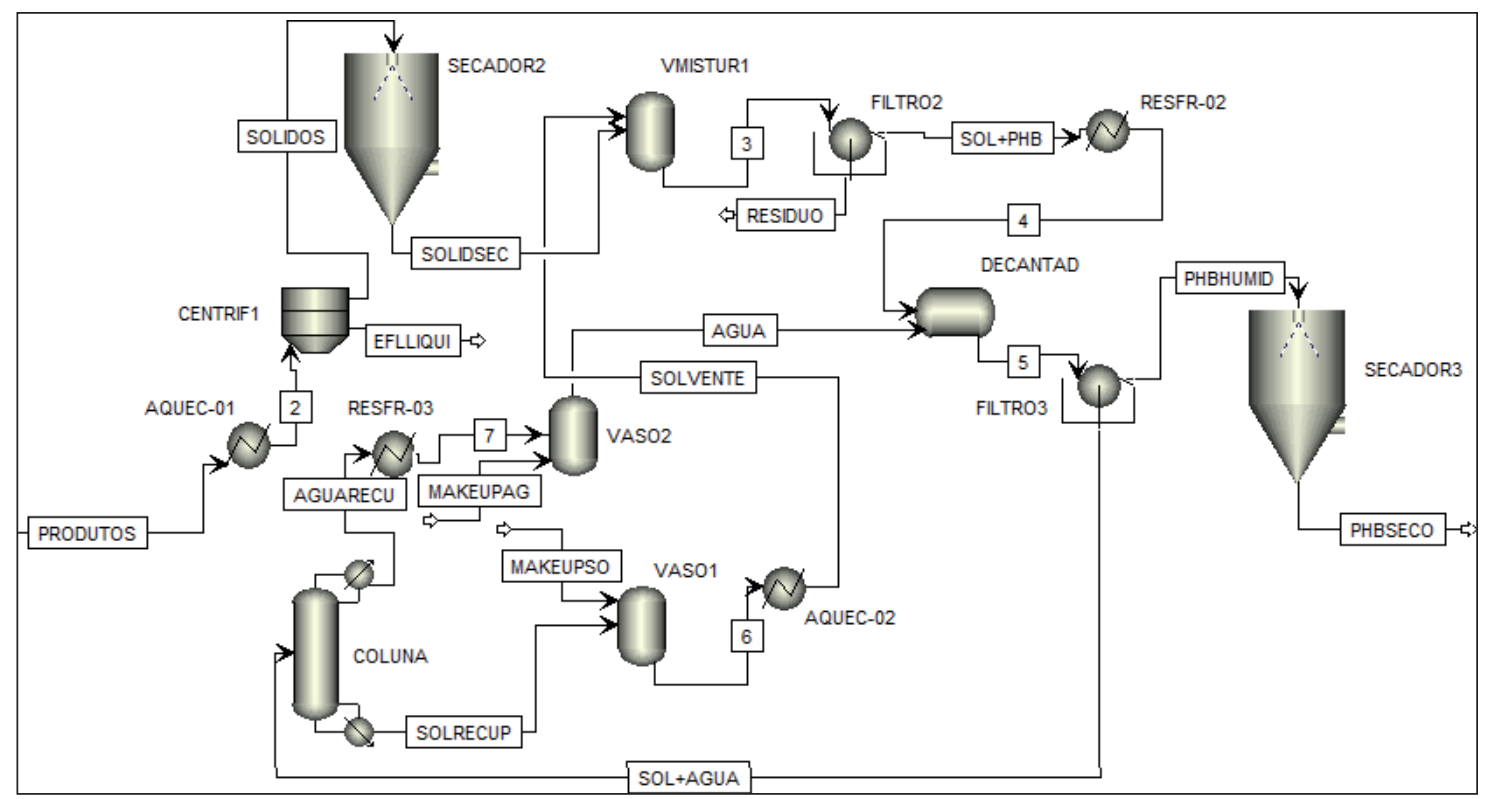

Figura 5: Fluxograma do processo de produção de PHB - Etapa depois do biorreator Fonte: Simulador Aspen Plus versão 8.8

um resfriador (RESFR-02), visto que, esta corrente teve sua temperatura elevada devido ao aquecimento prévio e à extração com o solvente a alta temperatura.

A corrente resultante do resfriador RESFR-02 passa por um vaso de decantação (DECANTAD) onde adiciona-se outro solvente, a água, o qual auxilia para que o PHB fique em suspensão na solução carbonato de propileno + água. Assim, o material de saída desse vaso passa por outra etapa de filtração (FILTRO3). O PHB é retido nesse filtro e sai com um certo teor de umidade.

Por fim, tem-se a etapa de secagem (SECADOR3), a qual consiste em diminuir o teor de umidade contido no produto final, o PHB. Do site da biocycle (nome comercial do PHB produzido pela PHB industrial), tem-se a informação que o produto sai com um teor de umidade de $0,3 \%$ $(\mathrm{m} / \mathrm{m})$ em base seca e, dessa forma, a corrente resultante da secagem contém PHB a 99,7\% (m/m) de pureza e 0,3\% $(\mathrm{m} / \mathrm{m})$ de umidade.

A Figura 5 exemplifica e sumariza os processos descritos anteriormente.

A corrente de permeado resultante do terceiro filtro (FILTRO3), que contêm carbonato de propileno e água, segue para a coluna de destilação (COLUNA). O objetivo nessa etapa é recuperar o carbonato de propileno utilizado na etapa de extração do PHB. Na destilação, $5 \%(\mathrm{~m} / \mathrm{m})$ do carbonato de propileno, contido na corrente de entrada, sai na corrente de topo junto com a água, ou seja, $95 \%$ $(\mathrm{m} / \mathrm{m})$ do solvente que entra no equipamento é recuperado na corrente de fundo [15].

Há também os processos de "make-up" da água e do carbonato de propileno (VAS01 e VAS02). Esse processo consiste na reposição dessas substâncias, visto que $20 \%$ $(\mathrm{m} / \mathrm{m})$ do carbonato de propileno é perdido durante todo o processo [15]. Para a água, considerou essa porcentagem de perda é de $10 \%(\mathrm{~m} / \mathrm{m})[15]$.
Todos os dados mencionados anteriormente foram utilizados para o cálculo das vazões do processo com auxílio do software Excel.

\section{Simulação do processo e dimensionamento dos principais equipamentos}

Para o dimensionamento dos equipamentos, utilizou-se as fórmulas, relações e metodologias descritas por Seider et al., 2009 [16] com os preços de compra do mercado americano, definidos em dólar.

Nas etapas de simulação do processo, o software empregado foi o simulador Aspen Plus versão 8.8. Vale ressaltar que somente alguns equipamentos do processo foram simulados no software. Esses equipamentos foram a coluna de destilação, compressores, bombas e trocadores de calor. Para o dimensionamento e cálculo do custos dos outros equipamentos, como os vasos, biorreator, reator de inoculação, filtros e centrífugas, foram utilizados os dados da literatura e as vazões mássicas foram encontradas a partir do balanço de massa.

\section{Cálculo do investimento total}

Para o cálculo do investimento total, foram considerados os investimentos fixos mais o capital de giro. $\mathrm{O}$ investimento fixo é a soma dos investimentos indiretos e diretos, mais a comissão do contratante e a contingência. Os critérios utilizados para o cálculo desses investimentos seguiram a metodologia descrita em Peters e Timmerhaus (1991) [17]. Dessa forma, o cálculo é baseado em fatores de razão aplicados ao custo dos equipamentos principais do processo. Os fatores utilizados foram para uma planta de processamento sólido/líquido. Esses fatores e critérios podem ser vistos na Tabela 2. 
Tabela 2: Critérios utilizados para o cálculo dos investimentos

\begin{tabular}{|c|c|c|}
\hline & Item & Porcentagem \\
\hline \multirow{9}{*}{$\begin{array}{l}\text { Custos } \\
\text { diretos }\end{array}$} & Equipamentos principais (C.E.P) & 100 \\
\hline & Instalação dos equipamentos & 39 \\
\hline & Instrumentação e controle & 13 \\
\hline & Instalação das tubulações & 31 \\
\hline & Instalação elétrica & 10 \\
\hline & Construção & 29 \\
\hline & Melhorias na planta & 10 \\
\hline & Instalação de serviço & 55 \\
\hline & Terreno & 6 \\
\hline \multirow{7}{*}{$\begin{array}{l}\text { Custos } \\
\text { indiretos }\end{array}$} & Engenharia e supervisão & 32 \\
\hline & Despesa de construção & 34 \\
\hline & Comissão do contratante & 5 \\
\hline & Contingência & 10 \\
\hline & Capital de giro & 15 \\
\hline & Investimento fixo & $\begin{array}{c}\text { Custos diretos } \\
+ \text { indiretos + } \\
\text { contingência }\end{array}$ \\
\hline & Investimento total (I.T) & $\begin{array}{c}\text { Investimento } \\
\text { fixo + capital } \\
\text { de giro }\end{array}$ \\
\hline
\end{tabular}

\section{Cálculo dos custos fixos}

Os custos fixos são aqueles que independem da capacidade de produção da planta. Estes foram calculados utilizando também os critérios mostrados em Peters e Timmerhaus (1991) [17] e podem ser vistos na Tabela 3. O custo de mão de obra de operação (MOO) foi calculado considerando-se a operação da planta durante 12 meses no ano, com 20 funcionários, também baseado na metodologia utilizada pelos autores citados anteriormente.

Tabela 3: Critérios utilizados para o cálculo dos custos fixos

\begin{tabular}{|c|c|}
\hline Itens & Critério \\
\hline Mão de obra de operação & 2000 USD/mês trabalhador \\
\hline Supervisão direta/administrativo & $17,5 \%$ MOO \\
\hline Manutenção e reparos & $6 \%$ IT/ano \\
\hline Suprimentos operacionais & $0,75 \%$ IT/ano \\
\hline Taxa de laboratório & $15 \%$ MOO \\
\hline Seguro & $0,7 \%$ IT/ano \\
\hline $\begin{array}{c}\text { MOO: Mão de obra de operação } \\
\text { IT: Investimento total }\end{array}$ \\
\hline
\end{tabular}

\section{Cálculo dos custos das utilidades e energia (custos variáveis)}

Custos variáveis são os custos que dependem da capacidade de produção da planta. Vale ressaltar que, como o projeto de produção de $\mathrm{PHB}$ é integrado à indústria de lacticínios, o custo do soro do leite foi considerado nulo, visto que este é um efluente de produção.
É importante mencionar que tanto o vapor, quanto a água desmineralizada são produzidos na própria planta.

\section{Consumo de utilidades}

O consumo total de água de resfriamento (AGR) e vapor é dado pela soma do consumo individual dessas utilidades em cada trocador de calor. Esse consumo foi determinado através do simulador Aspen Plus v.8.8. Como o vapor é produzido na própria planta, foi necessário o cálculo do consumo de gás natural para sua produção. O consumo desse gás foi obtido também através da simulação, visto que já se tinha o valor da vazão total do consumo de vapor em t/ano.

O consumo do solvente utilizado na extração do PHB e dos sais usados como substratofoi obtido através das respectivas vazões encontradas no balanço de massa.

\section{Consumo de energia}

O consumo de energia das bombas, compressor e turbinas foi calculado através dos dados de potência, em $\mathrm{kW} / \mathrm{h}$, também obtidos no Aspen Plus v.8.8.

$\mathrm{O}$ custo total de cada utilidade e energia foi obtido através da multiplicação do valor do consumo anual pelo preço unitário.

\section{Cálculo do custo total e da receita}

O custo total foi determinado através da soma dos valores de custo fixo e custo variáveis. Já para a determinação da receita, esta foi obtida através da multiplicação da produção anual de PHB pelo preço de venda, somado a multiplicação da produção anual de whey protein pelo preço de venda.

\section{Critérios de Projeto e Fluxo de caixa}

Para se determinar a viabilidade econômica do projeto, observou-se os seguintes critérios:

VPL $>0$

TIR $\geq$ TMA

O VPL (Valor Presente Líquido) é a soma, a partir da data inicial de operação, dos saldos dos fluxos de caixa, descontando a taxa de juros.O VPL é dado pela Equação 1:

$$
V P L=\sum_{j=0}^{n} \frac{C_{j}}{(1+i)^{j}}-I
$$

Cj é o fluxo de caixa resultante, I o valor do investimento total e i é a taxa de juros bancário utilizada para o financiamento e manutenção do projeto. Este valor foi considerado sendo $9 \%$ a.a.

A TIR (Taxa Interna de Retorno) é definida como a taxa 
de juros que, em algum momento, igualará o valor presente das entradas aos da saída. Vale ressaltar que, em outras palavras, a TIR nada mais é que a taxa de retorno em relação aos valores de investimento em um negócio. Assim, a TIR pode ser determinada quando o VPL se iguala a zero. A TIR também representa a taxa de rentabilidade do projeto.

A Taxa Mínima de Atratividade, TMA, é a taxa em que um investimento é rentável e, assim, de baixo risco. Esta, atualmente, é consideradano Brasil como 15\% a.a. Para um investimento apresentar uma rentabilidade positiva, ou seja, ter uma taxa de retorno maior do que a de um investimento de baixo risco, a TIR deve ser maior ou igual que a TMA.

Com relação ao preço de venda do produto, este foi estimado de forma que os dois critérios mencionados fossem satisfeitos, VPL $>0$ e TIR $\geq$ TMA.

Com relação à depreciaçãodos equipamentos e bens dos ativos e imobilizados, esta foi considerada linear durante o tempo de operação da planta de 15 anos, visto que estes, com o passar do tempo, perdem seu valor por consequência do desgaste e obsolescência normal. A depreciação é dada pela Equação 2:

$D_{p}=\frac{I-V_{R}}{T_{\text {operação }}}$

Sendo que I é o investimento e $\mathrm{V}_{\mathrm{R}} \mathrm{O}$ valor residual. $\mathrm{O}$ valor residual da planta foi considerado de $1 \%$ em relação ao investimento total. Esse valor corresponde ao capital que pode ser adquirido após a inatividade da planta, como por exemplo, venda de alguns equipamentos para o aproveitamento do metal de construção.O valor residual é dado pela Equação 3:

$V_{R}=0,01 . I$

Os impostos foram considerados como sendo $34 \% \mathrm{em}$ relação ao Lucro bruto [18].

O fluxo de caixa foi determinado como descrito na Tabela 4:

Tabela 4: Equações utilizadas no fluxo de caixa

\begin{tabular}{|c|c|}
\hline Fluxo de caixa & Equação \\
\hline Receita $(R)$ & Preço x Produção \\
\hline Custo variável $\left(C_{\mathrm{v}}\right)$ & - \\
\hline Custos fixos $\left(\mathrm{C}_{\mathrm{F}}\right)+$ Depreciação $\left(\mathrm{D}_{\mathrm{p}}\right)$ & - \\
\hline Lucro bruto $\left(\mathrm{L}_{\mathrm{b}}\right)$ & $\mathrm{L}_{\mathrm{b}}=\mathrm{R}-\left(\mathrm{C}_{\mathrm{v}}+\mathrm{C}_{\mathrm{F}}+\mathrm{D}_{\mathrm{p}}\right)$ \\
\hline Impostos $(\mathrm{Imp})$ & $0,34 \mathrm{~L}_{\mathrm{b}}$ \\
\hline Lucro líquido $\left(\mathrm{L}_{\mathrm{l}}\right)$ & $\mathrm{L}_{\mathrm{l}}=\mathrm{L}_{\mathrm{b}}-\mathrm{Imp}$ \\
\hline Depreciação $\left(\mathrm{D}_{\mathrm{p}}\right)$ & - \\
\hline Geração de caixa $\left(\mathrm{G}_{\mathrm{c}}\right)$ & $\mathrm{G}_{\mathrm{c}}=\mathrm{L}_{\mathrm{l}}+\mathrm{D}_{\mathrm{p}}$ \\
\hline Investimento total $(\mathrm{IT})$ & - \\
\hline Valor residual $\left(\mathrm{V}_{\mathrm{r}}\right)$ & $0,01 \mathrm{IT}$ \\
\hline Fluxo de caixa $\left(\mathrm{C}_{\mathrm{j}}\right)$ & $\mathrm{C}_{\mathrm{j}}=\mathrm{G}_{\mathrm{c}}+\mathrm{V}_{\mathrm{r}}-\operatorname{Inv}$ \\
\hline
\end{tabular}

\section{Caracterização do soro de leite}

A composição do soro de leite utilizado no processo descrito está explicita na Tabela 5 a seguir:

Tabela 5:Composição aproximada do soro do leite

\begin{tabular}{|c|c|}
\hline Componente & Composição mássica \\
\hline Solução aquosa & $94,60 \%$ \\
\hline Proteína & $4,40 \%$ \\
\hline Lactose & $1,00 \%$ \\
\hline
\end{tabular}

Fonte: Berwig, Baldassoe Dettmer, 2016

Vale ressaltar que, em solução aquosa, têm-se os componentes sólidos que estão empouca quantidade como gorduras, cinzas e nitrogênio, os quais não foram considerados separadamente por motivos de facilidade nos cálculos e na simulação.

\section{Resultados e Discussão}

\section{Determinação da Capacidade de Produção}

A base de cálculo definida foi de uma produção de 1000 ton/ano de PHB. Essa produção foi escolhida como análise inicial desse processo, pois esta representa a produção de uma biorrefinaria integrada a indústria de lacticínio de médio porte. Como para $1 \mathrm{~kg}$ de queijo produzido, tem-se a obtenção de $9 \mathrm{~kg}$ de soro de leite [3] e, do balanço de massa efetuado, tem-se a informação que, para a produção de 1000 ton/ano de PHB, são necessárias 73.358,17 ton/ ano de soro de leite, desta forma, diante dos dados mencionados, é estimável que o processo tem que estar integrado a uma indústria de lacticínios com um processamento diário equivalente a $250000 \mathrm{~L}$ leite / dia, ou seja, uma fábrica de laticínios de médio porte [19].

\section{Validação do modelo usado na simulação}

O modelo utilizado para o equilíbrio líquido-vapor do carbonato de propileno e da água foi o UNIQUAC (UNIversal QUAsi Chemical). Esse modelo foi escolhido, pois se adequa e é bem aplicável a uma série de misturas líquidas. O UNIQUAC foi desenvolvido por Abrams e Prausnitz (1975) [20] e, basicamente, em seu cálculo, para estimar o tamanho e área das superfícies externas das moléculas, são utilizados parâmetros dos componentes puros da mistura. Além disso, deve-se ressaltar que, com relação aos parâmetros ajustáveis, este modelo utiliza apenas dois por binário.

A escolha do modelo pode ser justificada também, pois, segundo Prausnitz, Lichtenthaler e De Azevedo (1999) [21], este é aplicável em misturas não-eletrolíticas, podendo ter fluidos polares ou apolares. Cabe frisar também que o UNIQUAC consegue reproduzir bem sistemas de baixa ou moderada pressão. Portanto, diante do exposto 
e considerando que, a coluna opera à pressão atmosférica e o binário é composto pelo carbonato de propileno, um solvente orgânico polar e água, outro solvente, porém inorgânico polar, pressupôs-se que o modelo UNIQUAC se adequaria bem ao sistema descrito.

Do simulador, utilizando o modelo UNIQUAC, retirouse dados de pressão para diversas composições do binário água e carbonato de propileno. Posteriormente, essas pressões foram comparadas aos dados experimentais do binário, retirados da base de dados DECHEMA (1982). Os resultados podem ser vistos na Figura 6.

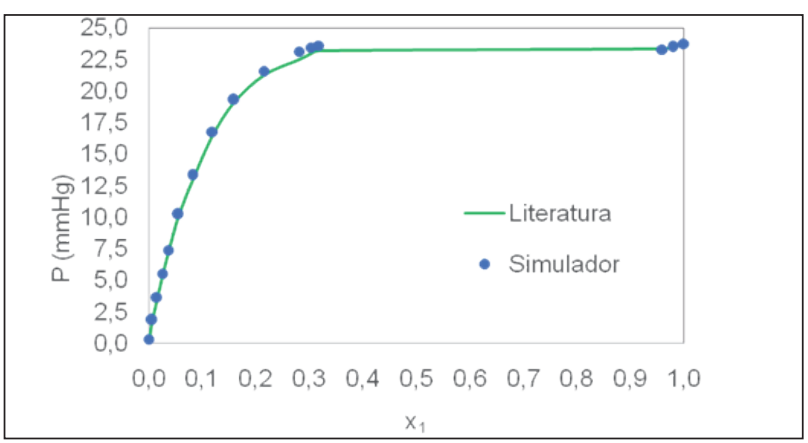

Figura 6: Pressão versus $\mathrm{x}_{1}$ - Gráfico da validação de dados para o modelo UNIQUAC e o binário água e carbonato de propileno

Como visto na Figura 6, observa-se que o modelo UNIQUAC se adequo bem aos dados experimentais, pois os pontos retirados do simulador seguem a mesma tendência daqueles encontrados na literatura, ajustando-se bem. Além disso, observa-se que o modelo representou melhor os dados reais na região de baixas pressões.

\section{Custos dos equipamentos}

A Tabela 6 mostra o custo dos equipamentos do processo. Esse custo já está corrigido com o valor da taxa média de inflação americana (período: 2010-2017), sendo essa, aproximadamente, $1,70 \%$ [22].

Tabela 6: Custo dos equipamentos do processo

\begin{tabular}{|c|c|}
\hline Equipamento & Custo (USD) \\
\hline Coluna de destilação & 122.975 \\
\hline Vasos & 965.450 \\
\hline Biorreator & 441.780 \\
\hline Reator de inoculação & 176.174 \\
\hline Filtros e Centrífugas & 585.412 \\
\hline Secadores & 999.809 \\
\hline Compressor & 460.873 \\
\hline Bombas & 152.752 \\
\hline Trocadores & 396.652 \\
\hline Turbinas & 426.448 \\
\hline Total & 4.728 .329 \\
\hline
\end{tabular}

O preço e o custo das principais matérias-primas, insumos e sais usados no processo podem ser vistos nas Tabelas 7 e 8 .
Tabela 7: Preço das principais matérias-primas e insumos usados no processo

\begin{tabular}{|c|c|c|}
\hline Matéria-prima & Valor (USD/ton) & Fonte \\
\hline $\mathrm{KH}_{2} \mathrm{PO}_{4}$ & 800 & Alibaba, $2018{ }^{[23]}$ \\
\hline$\left(\mathrm{NH}_{4}\right)_{2} \mathrm{HPO}_{4}$ & 746 & Alibaba, $2018^{[23]}$ \\
\hline $\mathrm{MgSO}_{4} \cdot 7 \mathrm{H}_{2} \mathrm{O}$ & 100 & Alibaba, $2018^{[23]}$ \\
\hline Ácido cítrico & 600 & Alibaba, $2018^{[23]}$ \\
\hline $\mathrm{HCl}$ & 200 & Alibaba, $2018^{[23]}$ \\
\hline $\mathrm{FeSO}_{4} \cdot 7 \mathrm{H}_{2} \mathrm{O}$ & 80 & Alibaba, $2018^{[23]}$ \\
\hline $\mathrm{CaCl}_{2}$ & 120 & Alibaba, $2018^{[23]}$ \\
\hline $\mathrm{ZnSO}_{4} \cdot 7 \mathrm{H}_{2} \mathrm{O}$ & 350 & Alibaba, $2018^{[23]}$ \\
\hline $\mathrm{MnSO}_{4} 7 \mathrm{H}_{2} \mathrm{O}$ & 400 & Alibaba, $2018^{[23]}$ \\
\hline $\mathrm{CuSO}_{4} \cdot 5 \mathrm{H}_{2} \mathrm{O}$ & 1550 & Alibaba, $2018^{[23]}$ \\
\hline$\left(\mathrm{NH}_{4}\right)_{6} \mathrm{Mo}_{7} \mathrm{O}_{24} 4 \mathrm{H}_{2} \mathrm{O}$ & 11000 & Alibaba, $2018^{[23]}$ \\
\hline $\mathrm{Na}_{2} \mathrm{~B}_{4} \mathrm{O}_{7} \cdot 10 \mathrm{H}_{2} \mathrm{O}$ & 645 & Alibaba, $2018^{[23]}$ \\
\hline \multicolumn{3}{|c|}{ Insumos } \\
\hline AGR & 0,57 & - \\
\hline Energia & 0,08 & - \\
\hline Gás natural & 192,5 & AliceWeb $2018^{[24]}$ \\
\hline Solvente $\mathrm{C}_{4} \mathrm{H}_{6} \mathrm{O}_{3}$ & 900 & Alibaba, $2018{ }^{[23]}$ \\
\hline Água & 1,67 & - \\
\hline
\end{tabular}

Tabela 8: Custo das principais matérias-primas e insumos usados no processo

\begin{tabular}{|c|c|c|}
\hline Insumo & Cantidade & Valor USD/ano \\
\hline AGR & ton & 2.093 .956 \\
\hline Energia & kWh & 218.606 \\
\hline Vapor & ton & 1.783 .541 \\
\hline Solvente & ton & 2.395 .980 \\
\hline Água & ton & 7.409 \\
\hline Sais & ton & 37.118 \\
\hline Total & & 6.536 .612 \\
\hline
\end{tabular}

Os valores apresentados na tabela para o preço de produção da AGR, energia e água desmineralizada são valores referenciais provindos do Polo Industrial, localizado na cidade de Camaçari, no estado da Bahia, no Brasil.

Já os valores obtidos pela análise do fluxo de caixa, como VPL, tempo de operação, custos variáveis, custos fixos, receita e investimento total, são apresentados na Tabela 9.

Tabela 9: Resultados da análise econômica

\begin{tabular}{|c|c|}
\hline Grandeza & Valor \\
\hline Tempo de operação & 15 (anos) \\
\hline Investimento Total & 22.996 .476 (USD) \\
\hline Custo variável & 6.536 .612 (USD/ano) \\
\hline Custo fixo & 2.181 .874 (USD/ano) \\
\hline Receita PHB & 5.000 .000 (USD/ano) \\
\hline Receita WHEY & 9.771 .170 (USD/ano) \\
\hline \multicolumn{2}{|c|}{ VPL } \\
\hline TIR & 15 (\%) a.a \\
\hline PHB: Preço de venda & 5.000 (USD/ton) \\
\hline WHEY: Preço de venda & 12000 (USD/ton) \\
\hline
\end{tabular}

Com o resultados da Tabela 9, nota-se que, atingir os critérios econômicos num período de operação de 15 anos o preço de venda do PHB teria que ser 5000 USD/ton e da proteína 12000 USD/ton, o que tornaria viável o projeto, 
pois o valor de mercado do PHB no Brasil não ultrapassa os 5000 USD/ton [25] e o da proteína está entre 10000 e $13000 \mathrm{USD} /$ ton [26].

\section{Análises de sensibilidade}

Efetuou-se uma análise de sensibilidade para verificar o comportamento VPL e da TIR com relação a variação da escala de produção. Assim, o limite inferior de produção, 200 t/ano, visou à representação das indústrias de laticínio de pequeno porte (processamento diário de cerca de $50 \mathrm{mil}$ litros de leite) e o superior, 10000 t/ano, visou às de grande porte (processamento diário de cerca de 2 milhões de litros de leite). Os resultados dessa análise podem ser vistos nas Figuras 7 e 8.

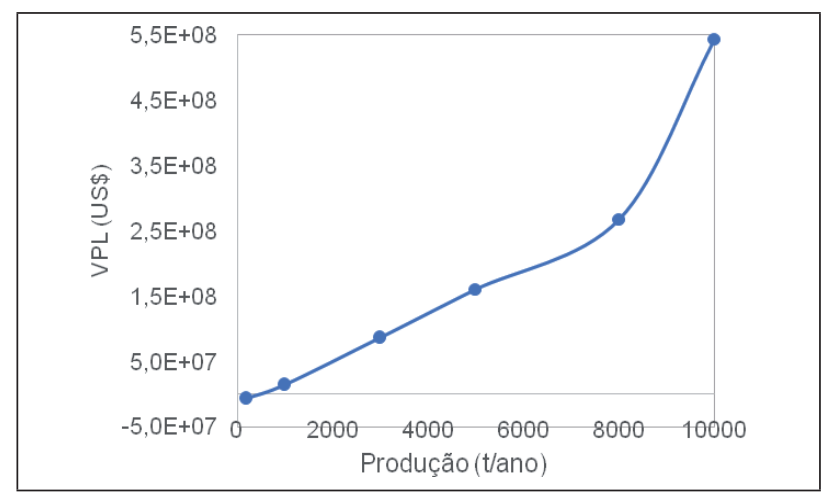

Figura 7: VPL versus Produção de PHB

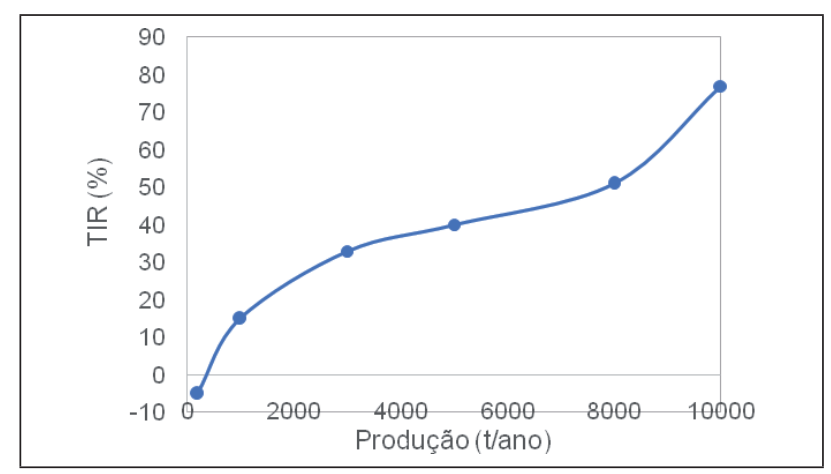

Figura 8: TIR versus Produção de PHB

Diante dos resultados apresentados nas Figuras 7 e 8 , percebe-se que, à medida em que a produção aumenta e fixando-se os preços de venda do PHB e da proteína, o investimento se torna economicamente mais viável, alcançando maiores valores de VPL e taxa interna de retorno bruto, quando comparado a outros empreendimentos de menor capacidade de produção. Nota-se que, para fábricas de laticinios de pequeno porte (com processamento diário de no máximo 125000 litros de leite), o projeto apresenta tanto o VPL quanto a TIR negativas, representando inviabilidade econômica para empreendimentos desse porte.

Outra análise efetuada foi com relação ao preço do solvente, visto que, como observado na Tabela 10, o custo do carbonato de propileno representa $43,55 \%$ do custo variável total. Assim, é importante avaliar e analisar a viabilidade do projeto no que se refere à variação de preço desse solvente.

Tabela 10: Porcentagem relativa dos insumos em relação aos custos totais variáveis

\begin{tabular}{|c|c|}
\hline Insumo & $\begin{array}{c}\text { Custos totais } \\
\text { Variáveis = 100 \% }\end{array}$ \\
\hline AGR & $28,55 \%$ \\
\hline Energia & $2,98 \%$ \\
\hline Vapor & $24,31 \%$ \\
\hline Solvente & $43,55 \%$ \\
\hline Água & $0,10 \%$ \\
\hline Sais & $0,51 \%$ \\
\hline
\end{tabular}

Os resultados para essa análise podem ser vistos nas Figuras 9 e 10.

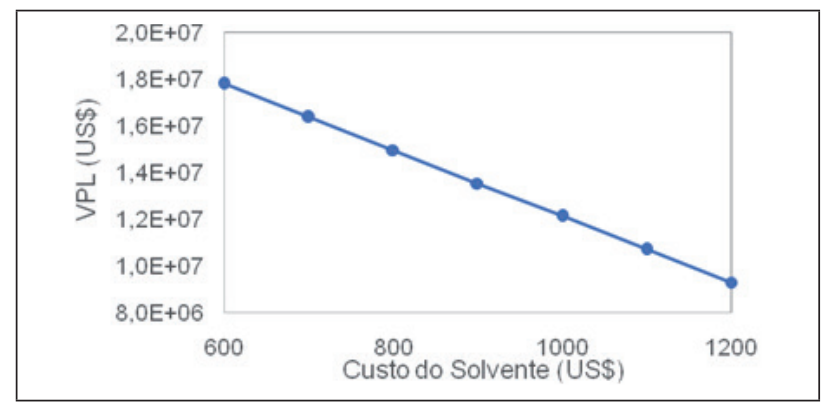

Figura 9: VPL versus Custo do Solvente (USD)

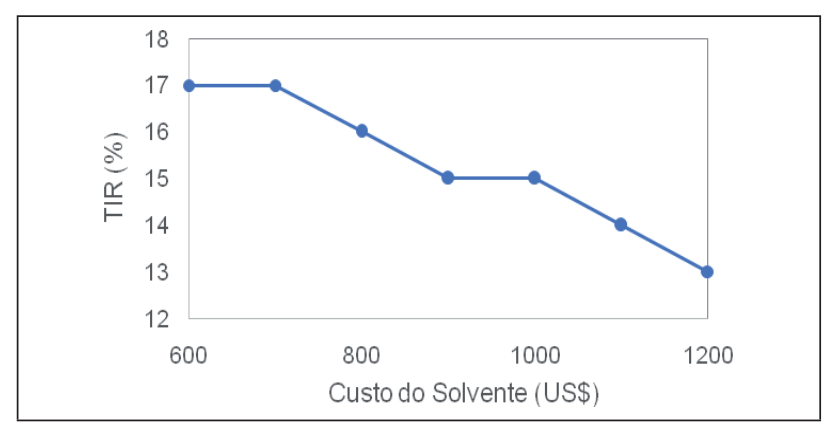

Figura 10: TIR versus Custo do Solvente (USD)

Como mostrado nas Figuras 9 e 10, o aumento no preço do solvente da 900 a 1200 USD (33\%), mantêm o VPL na faixa dos 10 milhões de dólares e provoca uma diminuição de TIR de $15 \%$ a $13 \%$ (2\%). Isso indica que o projeto absorve bem possíveis aumentos no seu principal custo variável, mantendo-se economicamente atrativo.

\section{Conclusões}

Baseado na análise dos resultados obtidos, conclui-se que a instalação de uma biorrefinaria integrada à indústria que processa 250000 litros de leite / dia no Brasil, para a produção de PHB e proteína a partir do soro do leite, utili- 
zando a metodologia de processo descrita, é tecnicamente e economicamente viável. Além disso, a partir da análise de sensibilidade foi perceptível que à medida em que a produção aumenta, fixando-se os preços de venda do PHB (5.000 USD/ton) e da proteína (12.000 USD/ton), o projeto se torna economicamente mais viável.

\section{Nomenclatura}

AGR - Água de resfriamento

C.E.P - Custo dos equipamentos principais

$\mathrm{C}_{\mathrm{F}-}$ Custos fixos

$\mathrm{Cj}$ - Fluxo de caixa

$\mathrm{C}_{\mathrm{v}}$ - Custo variável

$\mathrm{D}_{\mathrm{p}}$ - Depreciação

$\mathrm{G}_{\mathrm{c}}-$ Geração de caixa

I.T - Investimento Total

i - Taxa de juros bancária

ID - Investimento direto

IF - Investimento fixo

Imp - Imposto

$\mathrm{L}_{\mathrm{b}}$ - Lucro bruto

$\mathrm{L}_{1}$ - Lucro líquido

M.O.O - Mão de obra de Operação

PHB - Poli (3-Hidroxibutirato)

R - Receita

TIR - Taxa Interna de Retorno

TMA - Taxa Mínima de Atratividade

VPL - Valor Presente Líquido

$\mathrm{V}_{\mathrm{R}}-$ Valor residual

\section{Referências}

1. Nali, E. C.; Ribeiro, L. B. N. M.; Hora, A. B. Biorrefinaria integrada à indústria de celulose no Brasil: oportunidade ou necessidade? BNDES Setorial, Rio de Janeiro, n.43, p. 257 - 294, mar. 2016.

2. Foelkel, c. As biorrefinarias integradas no setor brasileiro de fabricação de celulose e papel de eucalipto. Eucalyptus Online Book \& Newsletter, rev., 2015.

3. Queiroz, S. F.; Mata, J. F.; Emerenciano, O. F. Produção de leite e queijo bovino da indústria laticinistaMiraleite no Triângulo Mineiro. Cadernos de pós-graduação da FAZU, Minas Gerais, v. 2, 2011. Disponível em: $<$ http://www.fazu.br/ojs/index.php/posfazu/article/ viewFile/417/309> Acesso em: 22 nov. 2018.

4. Rhim, J. W.; Park, H. M.; Ha, C. S. Bio-nanocomposites for food packaging applications. Progress in Polymer Science, v. 38, p. 1629-1652, 2013.

5. Sivakumar, N.; Al-Bahry, S.; Al-Battashi, H. S. Screening of Biopolymer Producing Bacteria Isolated from Some Brassica Plants. APCBEE Procedia, [S.I.], v. 5, p. 333-338, 2013.

6. Kloss, J. R. Dionisio, J. A. Soil degradation study of polyurethanes elastomers based on poly (e-caprolactona) diol. In: XI Internacional Macromolecular Colloquium and 6th Internacional Smposium on Natural polymers and composites, Gramado-RS, v. único, 2007.

7. Byrom, D. Polymer synthesis by microorganisms: technology and economics. Trends in Biotechnology, v.5, p. 246-250, 1997.

8. Choi, M. H.; Yoon, S., c. Polyester biosynthesis characteristics of Pseudomonas citronellolis grown on various carbon sources, including 3-methyl-branched substrates. Applied and Environmental Microbiology, v. 60, p. 3245-3254, 1994.

9. Ahn, w. S.; Park, s. J.; Lee, S. Y. Production of Ply (3-Hydroxybutyrate) by Fed-Batch Culture of Recombinant Escherichia coli with a Highly Concentrated why Solution. Appliedand Environmental Microbiology, Chicago, v. 66, n. 8, p. 3624-3627, 2000.

10. Biocycle [Online], 2018. Disponívelem: $<$ http://www.biocycle.com.br/site.htm>.Acessoem:15de nov. 2018.

11. Berwig, H. K.; Baldasso, C.; Dettmer, A. Production and characterization of poly (3-hydroxybutyrate) generated by Alcaligenes latus using lactose and whey after acid protein precipitation process. Bioresource Technology, v. 218, p. 31-37, 2016.

12. Luz, B. G. Processo de extração das proteínas de soro de leite para a produção de concentrado proteico. ETech: Tecnologia para a Competitividade Industrial, Florianopolis, v. 9, n. 2, 2016.

13. Newnutrition. Whey Protein Isolado [Online], 2018. Disponível em: <https://www.newnutrition.com.br/proteinas/ whey-protein-isolado>. Acesso em: 18 de nov. 2018.

14. Quines, L. $\mathrm{K}$ et al. Extração de poli (3-hidroxibutirato), produzido por Cupriavidusnecator, com carbonato de propileno. Revista Química Nova, Santa Catarina, v. 38, n. 2, p. 2014-2020, 2015.

15. Quines, L. $\mathbf{K}$ et al. Recuperação e reutilização do carbonato de propileno empregado no processo de extração de poli (3-hidroxibutirato). Revista Polímeros, Santa Catarina, n. 27, p. 20-26, 2017.

16. Seider, W. D.; Seader J. D.; Lewin, D. R.; Widagdo, S. Product and Process Design Principles: Synthesis, Analysis and Design. Wiley, $3^{\circ}$ edição, 2009.

17. Peters, M. S.; Timmerhaus, K. D. Plant Design and Economics for Chemical Engineers. McGraw-Hill, New York, 4 ed., 1991.

18. Heritage. Index of Economic Freedom [Online], 2018. Disponível em: <https://www.heritage.org/index/country/ brazil/>. Acesso em: 22 de nov. 2018.

19. Camapuã News. Camapuã terá indústria de lacticínio de médio porte, 2014. Disponívelem:<http:// w w w . c a m a p u a n ew s . com. br/noticia . php? $\operatorname{cod}=28587 \&$ title $=$ Camapu $\% \mathrm{E}>$ Acesso em: 26 de nov. 2018.

20. Abrams, D. S., Prausnitz, J. M. StatisticalThermodynamicsofLiquid Mistures: A New Expression for the Excess Gibbs Energy of Partlyor Completely Systems. AIChe- 
Journal, v. 21, 116, 1975.

21. Prausnitz, J. M., Lichtenthaler, R. N., De Azevedo, E. G. Molecular Thermodynamicof Fluid-Phase Equilibria. Prentice-Hall, 1999.

22. Global Rates. Inflation United States - Consumer price index (CPI) [Online], 2018. Disponívelem: $<$ https://www.globalrates.com/economic-indicators/inflation/consumerprices/cpi/united-states.aspx $>$ Acesso em: 27 de nov. 2018.

23. Alibaba [Online]. Disponívelem: $<$ https://portuguese.alibaba.com/> Acesso em: 29 out. 2018.
24. Aliceweb. Análise das informações de comércio exterior [Online]. Disponível em: <www.http://aliceweb.mdic.gov. br/> Acesso em: 29 out. 2018.

25. MRE. Ministério das relações exteriores [Online]. Disponível em: $<$ https://sistemas.mre.gov.br/kitweb/datafiles/Toquio/pt-br/file/Bioplasticos07.pdf $>$ Acesso em: 28 out. 2018.

26. Dairy for Global Nutrition. Price per kilogramo protein [Online]. Disponível em: <http://www.dairyglobalnutrition.org/ price-and-supply-trends/dairy-price-trends $>$ Acesso em: 28 out. 2018. 